OPEN ACCESS

Edited by:

Jadson Diogo Pereira Bezerra, Universidade Federal de Goiás, Brazil

Reviewed by:

César Marín,

Universidad de O'Higgins, Chile

Mark Anthony,

ETH Zürich, Switzerland

*Correspondence:

Guoying Zhou

zhougy@nwipb.cas.cn

Specialty section: This article was submitted to

Fungi and Their Interactions,

a section of the journal

Frontiers in Microbiology

Received: 01 July 2020 Accepted: 18 September 2020

Published: 16 October 2020

Citation:

Xiao Y, Li C, Yang Y, Peng Y, Yang $Y$ and Zhou G (2020) Soil Fungal

Community Composition, Not Assembly Process, Was Altered by Nitrogen Addition and Precipitation

Changes at an Alpine Steppe.

Front. Microbiol. 11:579072. doi: 10.3389/fmicb.2020.579072

\section{Soil Fungal Community Composition, Not Assembly Process, Was Altered by Nitrogen Addition and Precipitation Changes at an Alpine Steppe}

\author{
Yuanming Xiao ${ }^{1,2}$, Changbin Li $^{1,2}$, Yang Yang ${ }^{1,2}$, Yunfeng Peng ${ }^{3}$, Yuanhe Yang ${ }^{3}$ and \\ Guoying Zhou ${ }^{1,4,5 *}$
}

${ }^{1}$ Northwest Institute of Plateau Biology, Chinese Academy of Sciences, Xining, China, ${ }^{2}$ College of Life Sciences, University of Chinese Academy of Sciences, Beijing, China, ${ }^{3}$ State Key Laboratory of Vegetation and Environmental Change, Institute of Botany, Chinese Academy of Sciences, Beijing, China, ${ }^{4}$ Key Laboratory of Tibetan Medicine Research, Chinese Academy of Sciences, Xining, China, ${ }^{5}$ Qinghai Key Laboratory of Qinghai-Tibetan Plateau Biological Resources, Xining, China

Global climate change and nitrogen deposition have been having broad impacts on microorganisms. On the Qinghai-Tibetan Plateau (QTP), the responses of soil microbial community assemblage and diversity to nitrogen deposition and changes in precipitation are poorly understood, especially in the alpine steppe. In this study, we conducted a field manipulative experiment of nitrogen deposition and precipitation amount in an alpine steppe on the northeastern QTP and investigated the responses of community composition, diversity, and community assemblage of soil fungi. Soil fungal community compositions were significantly altered under nitrogen addition, precipitation change, and their interaction, and positively related with soil moisture, soil pH, and plant species richness. However, they were negatively related to soil mineralizable $\mathrm{N}$ and soil available $\mathrm{P}$ content. Operational taxonomic units (OTU) richness and Chao 1 index decreased under nitrogen addition combined with precipitation reduction treatment, whereas the Shannon-Wiener index declined only under precipitation increment treatment. Convergent fungal community assembly processes were not acutely altered by both nitrogen addition and precipitation changes, indicating that environmental filtering was a dominant ecological process controlling fungal community assemblage. By elucidating the above questions, the study enhanced our ability to predict the responses of soil fungal communities to nitrogen deposition and precipitation changes at alpine steppes on the QTP in the future.

Keywords: soil fungi, phylogenetic community structure, community assembly, climate change, structural equation model

\section{INTRODUCTION}

Dominant ecological processes controlling soil microbial community assemblage have attracted extensive attention (Dini-Andreote et al., 2015). Evaluating the relative importance of deterministic and stochastic ecological processes in community assembly is a primary work for exploring community assembly (Dumbrell et al., 2010; Nemergut et al., 2013; Mori et al., 2015; Feng et al., 2018; Luo et al., 2019; Gao et al., 2020). For example, Beck et al. (2015) found 
that the deterministic and stochastic ecological processes jointly controlled fungal community assembly. Global changes have broad and profound impacts on microbial communities (Hutchins et al., 2019); for example, Chen et al. (2017) revealed that nitrogen addition enhanced the role of deterministic processes (i.e., environmental filtering) during soil arbuscular mycorrhizal fungal community assemblage in a temperate steppe. The Qinghai-Tibetan Plateau (QTP) is the largest and highest plateau in the world (average elevation, $>4,000 \mathrm{~m}$; area, $2.5 \times 10^{6} \mathrm{~km}^{2}$ ), and low temperature and strong evaporation are primary climatic features (Zheng and Zhao, 2017), which limit the rate of mineralization of soil organic matter and make this area more sensitive to global changes (e.g., nitrogen deposition and precipitation change). Soil fungi play important roles in accelerating biogeochemical cycles (Amend et al., 2015), maintaining the health of soil ecosystems (Frac et al., 2018), and regulating feedback between plants and soil (Semchenko et al., 2018) and are studied well in a global scale (Tedersoo et al., 2014; Davison et al., 2015), whereas it is still poorly understood on the QTP. Therefore, it is important that the responses of soil fungal diversity, community composition, and assemblage process to nitrogen deposition and precipitation change are explored on the QTP. Human activity-induced nitrogen deposition has triggered a lot of changes in ecological processes and environmental factors, such as soil available nitrogen, soil $\mathrm{pH}$, availability of soil phosphorus, and negative effects on biodiversity (Serna-Chavez et al., 2013; Lu et al., 2014; Chen et al., 2017). Soil environmental variables strongly affected soil fungal communities (Shen et al., 2013; Wang et al., 2017; Cho et al., 2019). On the QTP, nitrogen deposition has been presenting an increasing trend gradually, ranging from 0.87 to $1.38 \mathrm{~g} \mathrm{~N}$ $\mathrm{m}^{-2}$ year $^{-1}$ in the recent decade (Lü and Tian, 2007). Thus, soil fungi diversity might decline, and community composition might change significantly in the future. However, we still poorly understand how soil fungal diversity, community composition, and assemblage process respond to nitrogen deposition, and relationships between fungal community composition and soil environmental variables remain to be unclear. In addition to soil variables, plant diversity was also a factor affecting soil fungal community (Chen et al., 2017). Thus, examining relationships between soil fungal community and plant diversity is also important for comprehensively understanding the responses of soil fungal community to nitrogen deposition.

Precipitation changes also leave imprints on soil microbial community composition and assemblage (Leff et al., 2015; Zhang et al., 2017; Na et al., 2019). Wang et al. (2018) found that precipitation was a main driver for the distribution pattern and community structure of a soil fungal community at a temperate steppe in Inner Mongolia of China. Additionally, the negative effects of nitrogen deposition on biodiversity may be changed by the effects of elevated precipitation (Zhang et al., 2018). Precipitation has been occurring with an increasing trend gradually on the QTP (Yang, 2018), which might alleviate environmental drought pressure and then might benefit soil fungal diversity and community composition. However, the responses of soil fungal community composition, biodiversity, and assemblage process to the individual effect of precipitation change and interactions with nitrogen deposition are still poorly understood on the QTP. An alpine steppe is one of the main vegetation ecosystems on the QTP (Miehe et al., 2011; Figure 1A) and is more sensitive to climate change than other ecosystems (Zheng and Zhao, 2017). Therefore, alpine steppes are predicted to have stronger responses than other ecosystems to atmospheric nitrogen deposition and precipitation changes. In this study, nitrogen deposition and precipitation amounts were manipulated at an alpine steppe. High-throughput sequencing technology, beta diversity null modeling analysis (Powell et al., 2015), and co-occurrence network analysis (Barberán et al., 2012) were employed to investigate soil fungal community composition, diversity, and community assemblage process in response to nitrogen deposition and precipitation changes. The study examined the following questions: (1) whether soil fungal community composition and diversity were altered by nitrogen deposition, precipitation changes, and their interaction; (2) which environmental factors are significantly related with soil fungal community composition; (3) which ecological process, stochastic or deterministic process, played a dominant role in controlling soil fungal community assemblage and whether this dominant role was altered by nitrogen addition and precipitation changes. Through the examination of these questions, the study aimed to predict how the soil fungal community composition, diversity, and community assemblage processes will change under nitrogen deposition and precipitation changes in the future at an alpine steppe and to provide a theoretical basis for anthropogenic nitrogen source input and precipitation changes in alpine steppe management.

\section{MATERIALS AND METHODS}

\section{Study Site and Experimental Design}

The field experiment was performed in Gangcha County $\left(37^{\circ} 18^{\prime} \mathrm{N}, 100^{\circ} 15^{\prime} \mathrm{E}\right)$, which is located in Qinghai Province in the northeast of the QTP, China (Figure 1A). The altitude, mean annual temperature, and mean annual precipitation were 3,286 $\mathrm{m}, 0.08^{\circ} \mathrm{C}$, and $387 \mathrm{~mm}$, respectively. Alpine steppes are the dominant vegetation and comprised Stipa purpurea Grisebach, Poa crymophila Keng, and Leymus secalinus (Georgi) Tzvelev. The soil was classified as calcium soil order, semidry calcium soil suborder, and chestnut soil (Li et al., 2019).

The field experiment was established in 2013 by manipulating nitrogen deposition and precipitation to simulate atmospheric nitrogen deposition and precipitation changes due to climate change in the alpine steppe (Figure 1B). The experiment included six treatments, namely, $\mathrm{NP}-$ (ambient $\mathrm{N}$ with $50 \%$ precipitation reduction), NP (ambient $\mathrm{N}$ with ambient precipitation), $\mathrm{NP}+$ (ambient $\mathrm{N}$ with $50 \%$ precipitation increment), $\mathrm{N}+\mathrm{P}-(\mathrm{N}$ addition with $50 \%$ precipitation reduction), $\mathrm{N}+\mathrm{P}$ ( $\mathrm{N}$ addition with ambient precipitation), and $\mathrm{N}+\mathrm{P}+(\mathrm{N}$ addition with $50 \%$ precipitation increment). Five replicates for each treatment were established; thus, a total of 30 plots of $3.3 \mathrm{~m} \times 2.7 \mathrm{~m}$ in area were randomly separated in a $5 \times 6$ block design and divided by 2 m-wide buffer zones. V-shaped, sunlight-pervious, concave polyvinyl 


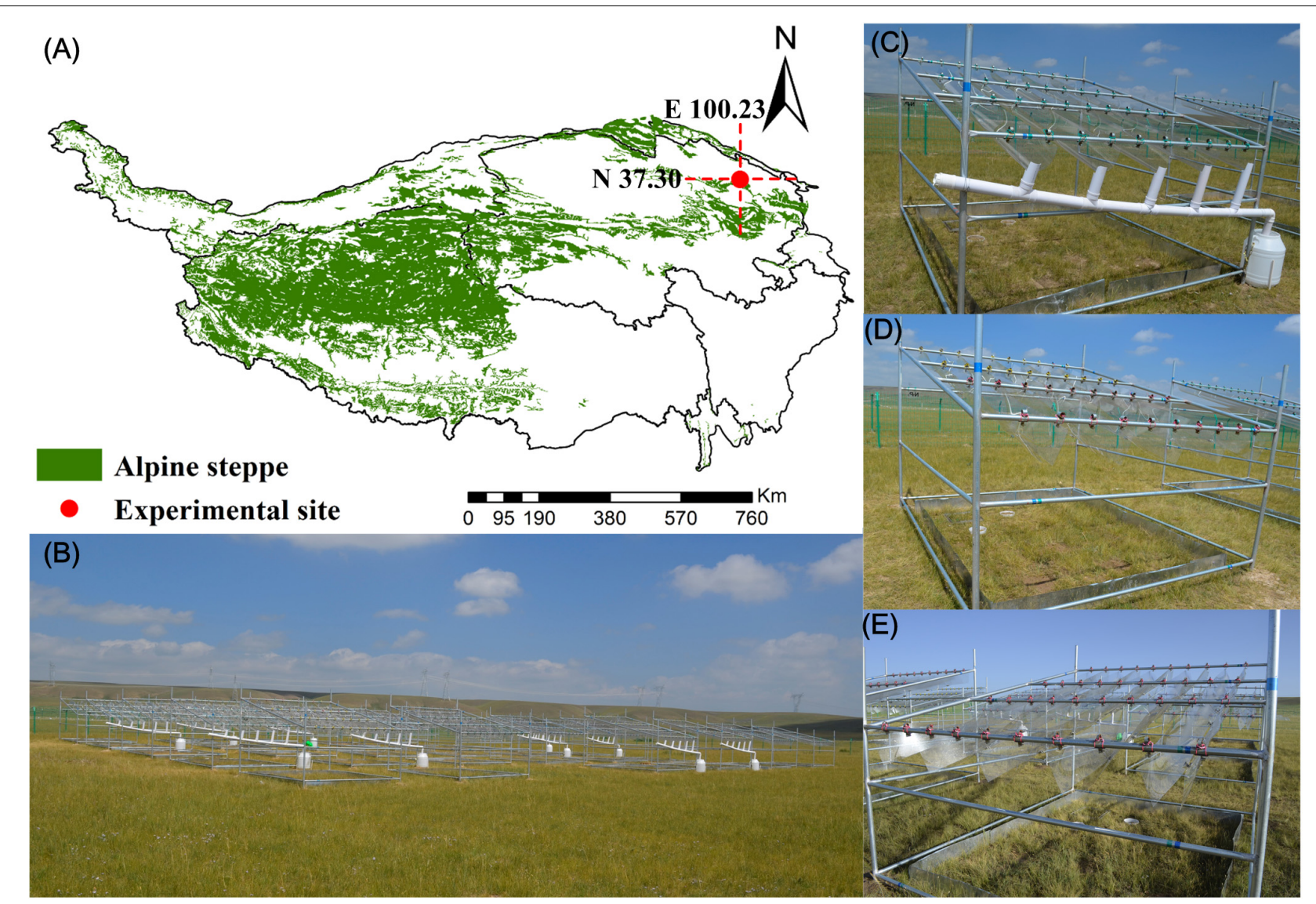

FIGURE 1 | Geographical location and photographs of the experimental site. (A) Geographical location; (B) overview of the experimental site; (C) 50\% precipitation reduction treatment; (D) 50\% precipitation addition treatment; (E) nitrogen addition treatment.

chloride (PVC) boards without slots, which were installed above treatments of $50 \%$ reduction in precipitation at a $15^{\circ}$ angle, were used to collect precipitation (Figure 1C). This precipitation was then transferred (sprinkling evenly) to the treatments of $50 \%$ increase in precipitation. For precipitation increments and ambient precipitation treatments, V-shaped, sunlight-pervious, concave PVC boards with slots were established above these plots (Ma et al., 2017) (Figures 1D,E). $\mathrm{NH}_{4} \mathrm{NO}_{3}$ was fertilized in the plots to simulate atmospheric nitrogen deposition $\left(10 \mathrm{~g} \mathrm{~N} \mathrm{~m}^{-2}\right.$ year $\left.^{-1}\right)$. Although nitrogen deposition will go up to $40 \mathrm{~g} \mathrm{~N} \mathrm{~m}^{-2}$ year $^{-1}$ by 2050 (Zong et al., 2016), $8 \mathrm{~g} \mathrm{~m}^{-2}$ year $^{-1}$ has led to $\mathrm{N}$ saturation in the soil in our study area concurrently (Peng and Yang, 2016). $\mathrm{NH}_{4} \mathrm{NO}_{3}$ was dissolved in $1 \mathrm{~L}$ of distilled water and sprinkled evenly twice into the plots of nitrogen addition during the peak growing season (midmonth of June and July). Identical amounts of distilled water were sprayed uniformly on the ambient nitrogen addition plots (Li et al., 2019).

\section{Plant Community Investigation and Soil Sampling}

Species richness under the different treatments was investigated in August (peak of biomass) using a $1 \mathrm{~m}^{2}$ quadrat and three replicates for each plot. The total species (non-repeat count) occurring in all three quadrats was used to represent the species richness for each plot. Numbers of each individual species were also recorded. Average relative abundance based on the three quadrats was calculated to represent abundance of each species. For soil sampling, five topsoil cores $(0-10 \mathrm{~cm})$ were randomly collected from each plot in August 2019 using a soil auger (diameter: $3.5 \mathrm{~cm}$, depth: $15 \mathrm{~cm}$ ) with sterilization. The five cores were mixed thoroughly using a $2.0 \mathrm{~mm}$ sieve to form a mixing sample without roots and debris, which was transported (at $4^{\circ} \mathrm{C}$ ) to the laboratory within $24 \mathrm{~h}$. Each mixing sample was divided into two parts; one was stored at $-80^{\circ} \mathrm{C}$ for DNA extraction, and the other part was air-dried for analysis of soil physicochemical properties.

\section{Soil Physicochemical Analyses}

Soil samples were dried at $105^{\circ} \mathrm{C}$ for $48 \mathrm{~h}$ to a constant weight to assess soil moisture. Soil $\mathrm{pH}$ was determined using a $\mathrm{pH}$ meter in a liquid supernatant with a soil-to-water ratio of 1:2.5. Soil organic carbon (SOC) contents were analyzed using a dichromate oxidation-titration method. Soil mineralizable nitrogen $(\mathrm{N})$ and soil available phosphorus $(\mathrm{P})$ and potassium $(\mathrm{K})$ contents were examined using the diffusion by alkali dissociation method, the ammonium molybdate method after extraction with $\mathrm{NaHCO}_{3}$ 
solution, and the flame atomic absorption spectrometric method, respectively (Bao, 2005). Soil mineralizable nitrogen $(\mathrm{N})$, available phosphorus $(\mathrm{P})$, and available potassium $(\mathrm{K})$ represent plant available N, P, and $\mathrm{K}$ contents in soil, respectively.

\section{DNA Extraction, Sequencing, and Bioinformatics Analysis}

An E.Z.N.A. Soil DNA Kit (Omega Bio-tek, Inc., Norcross, GA, United States) was used to extract soil genomic DNA from exactly $0.3 \mathrm{~g}$ of fresh soil according to the manufacturer's instructions; three replicates for each soil sample were established. The concentration and purity of the obtained DNA sample were determined using a NanoDrop 2000 spectrophotometer (Thermo Scientific, Wilmington, DE, United States). Primers ITS1F (5'-ACTTGGTCATTTAGAGGAAGTAA- $\left.3^{\prime}\right)$ and ITS2 (5'-BGCTGCGTTCTTCATCGATGC- $\left.3^{\prime}\right)$ were used to amplify fungal internal transcribed spacer-1 (ITS1) sequences (Adams et al., 2013). Details of the processes and reaction conditions for ITS1 amplification have been described in previous studies (Adams et al., 2013). Sequencing of DNA samples was conducted on an Illumina MiSeq PE300 instrument (Illumina, San Diego, United States) provided by Shanghai Majorbio Bio-Pharm Technology Co., Ltd.

Paired-ended sequence reads generated from the Illumina MiSeq PE300 were filtered by fastp (version 0.20.0; Chen et al., 2018) and merged using FLASH software (version 1.2.11; Magoč and Salzberg, 2011) with the following criteria: (i) 300 bp reads were truncated at any site receiving an average quality score of $<20$ over a $50 \mathrm{bp}$ sliding window, and truncated reads shorter than 50 bp were discarded; reads containing ambiguous characters were also discarded, and samples were distinguished according to the barcode and primers; (ii) only overlapping sequences longer than $10 \mathrm{bp}$ were assembled according to their overlapped sequence. The maximum mismatch ratio of the overlap region is 0.2 . Reads that could not be assembled were discarded; (iii) the sequence direction was adjusted, with exact barcode matching and two-nucleotide mismatch in primer matching. A total of 1,862,202 (99.31\%) sequences were obtained for the soil fungal community. Subsequently, operational taxonomic units (OTUs) were generated by clustering the sequences with $97 \%$ similarity using UPARSE (version 7.1; Edgar, 2013). The BLAST tool and UNITE database (version 8.0; Koljalg et al., 2013) was used to filter out potentially non-fungal taxa, and then the RDP Classifier version 2.2 (Wang et al., 2007) was used to annotate the most representative sequence of each OTU at a confidence threshold of 0.7. Finally, 3,423 OTUs, which were classified as 13 phyla, 45 classes, 101 orders, 220 families, and 416 genera, were detected across all samples. FUNGuild was used to match fungal functional profiles (Nguyen et al., 2016). All representative sequences in the study were deposited in the GenBank database with accession number PRJNA638547.

\section{Diversity and Phylogenetic Structure of Soil Fungal Community}

A rarefaction curve was used to evaluate sequencing depth (shown in Supplementary Figure S1). The OTU richness, Chao
1 index, and Shannon-Wiener index were used to assess alpha diversity of the soil fungal community. The Shannon-Wiener index evaluates species richness and evenness and is more sensitive to dominant species, whereas Chao 1 index is more sensitive to rare species. The $\mathrm{R}$ environment with the functions chao1() in the "fossil" package (Vavrek, 2011) and rowSums() and diversity() in the "vegan" package (Oksanen et al., 2019) was used to calculate the above diversity indices.

Abundance-based $\beta$-diversity null modeling analysis with community Bray-Curtis dissimilarity was used to detect soil fungal community assembly processes by evaluating the difference between "real" community and null modeling (neutral process) (Beck et al., 2015; Powell et al., 2015; Powell and Bennett, 2016). This difference was represented by effect size, which was calculated as follows (Mori et al., 2015):

Effect size $=\left[\beta\right.$ - diversity $_{o b s}-$ $\operatorname{mean}(\beta$-diversity null $)] / \beta$-diversity sd $_{\text {. }}$.

The $\beta$-diversity ${ }_{\text {obs }}$ represented the observed value of a "real" community, and the mean ( $\beta$-diversity null $_{\text {n }}$ ) represented the mean of null $\beta$-diversity distribution. The $\beta$-diversity sd represented the standard deviation of null $\beta$-diversity distribution. To get the null $\beta$-diversity distribution, each OTU in the community was drawn 999 times with the same probability from the OTU pool, which was represented by all of the OTUs occurring in the study. If effect size (relative to neutral prediction) was significantly greater (divergence) or lesser (convergence) than zero, it indicates that the deterministic processes (i.e., interspecific competition or environmental filtering) play leading roles in community assembly. If there was no significant difference between effect size and zero (random), it indicates that neutral factors (for example, dispersal limitations and homogenizing dispersal) control community assembly (Beck et al., 2015; Powell et al., 2015; Powell and Bennett, 2016). The above calculation processes were performed in R (R Core Team, 2015).

\section{Statistical Analysis}

Two-way analysis of variance (ANOVA) was used to determine the effects of nitrogen addition, precipitation alteration, interactions of nitrogen addition and precipitation alteration, and blocking variable on soil environmental factors, plant species richness, and relative abundance of fungal taxon. Significant differences of soil environmental factors, plant species richness, and relative abundance of fungal taxon (Supplementary Table S1) between treatments were examined using Tukey's test at $P<0.05$. To estimate the effects of treatments on soil fungal community composition, non-metric multidimensional scaling (NMDS) analysis was used to present visually the differences in soil fungal community composition. Additionally, permutational multivariate ANOVA (PERMANOVA) was conducted based on the Bray-Curtis distance matrix of community relative abundance using the adonis() function in the "vegan" package (Oksanen et al., 2019) to determine the effects of nitrogen addition, precipitation changes, nitrogen addition $\times$ precipitation changes, and random effect of block (blocking variable) on differences in soil fungal community composition. Spearman's correlation analysis using the cor.test () function was calculated to determine relationships between 
fungal community composition and environmental factors, and the response variable was the first axes of the NMDS.

A co-occurrence network was used also to explore the cooccurrence patterns in the study (Barberán et al., 2012). Before analysis, low-abundance OTUs (relative abundance $<0.005 \%$ ) were removed. The corr.test() function in the "psych" package (Revelle, 2018) was used to calculate Spearman's correlation based on the relative abundance table of soil fungal community, and only Spearman's correlation coefficient $>0.6$ or $<-0.6$ and $\boldsymbol{P}<0.05$ were included in the network (de Vries et al., 2018; Jiao et al., 2020). Gephi (version 0.9.2) ${ }^{1}$ was used to visualize the co-occurrence network.

\section{RESULTS}

\section{Soil Environmental Factors and Plant Community Characteristics}

Significant differences in soil moisture, soil $\mathrm{pH}$, SOC, plant available $\mathrm{N}, \mathrm{P}$ in soil, and plant species richness, but not in plant available $\mathrm{K}$ content in soil, were detected across the treatments (Table 1). Specifically, soil moistures were significantly higher in the precipitation increment treatments than in the precipitation reduction treatments, but there were no significant differences with NP (control) treatment. In comparison with NP (control) treatment, the nitrogen addition with precipitation reduction $(\mathrm{N}+\mathrm{P}-)$ treatment increased soil mineralizable $\mathrm{N}$ but reduced soil $\mathrm{pH}$ and plant species richness. SOC concentration was increased by nitrogen addition and was significantly higher than ambient nitrogen treatments. SOC was also the only environmental factor affected by the interaction of nitrogen addition and precipitation change. Soil available $\mathrm{P}$ content declined significantly under the nitrogen addition and precipitation increment $(\mathrm{N}+\mathrm{P}+)$ treatment, but no significant differences were found with the NP (control) treatment (Table 1).

${ }^{1}$ https://gephi.org/
Significant differences in plant community structure were also detected under different treatments (Supplementary Figure S2).

\section{Soil Fungi Abundance, Community Composition, and Diversity}

Relative abundances of soil fungi at the class level were significantly different across all the treatments (Figure 2 and Supplementary Table S1). Among groups with a relative abundance $>10.0 \%$, Agaricomycetes and Mortierellomycetes increased significantly under the precipitation increment treatments. In contrast, the abundance of Sordariomycetes declined under the precipitation increment treatments but increased significantly under nitrogen addition with precipitation reduction treatment (Figure 2 and Supplementary Table S1). Significant differences in fungal community composition were also detected under nitrogen addition, precipitation change, and interactive effects of nitrogen addition and precipitation change (Figure 3 and Table 3), in which precipitation change has the highest significant effect on community composition (Table 3 ).

Diversity analysis revealed that OTU richness and the Chao 1 index were lower under nitrogen addition combined with precipitation reduction $(\mathrm{N}+\mathrm{P}-)$ than under control (NP) and other treatments (Figures 4A,B), and the Shannon-Wiener index declined as a result of ambient nitrogen with precipitation increment treatment (Figure 4C). Precipitation change has a significant effect on all three indices, while the interaction of nitrogen addition and precipitation change has a significant effect only on the Shannon-Wiener index (Supplementary Table S3).

\section{Relationships Between Soil Fungal Community Composition and Soil Environmental Factors and Plant Species Richness}

Spearman's correlation analysis revealed that fungal taxon compositions were related positively and significantly to soil moisture content, soil $\mathrm{pH}$, and plant species richness but were

TABLE 1 | Soil environmental factors and plant species richness under nitrogen addition and precipitation changes.

\begin{tabular}{|c|c|c|c|c|c|c|c|}
\hline Treatment & $\begin{array}{c}\text { Soil moisture } \\
(\%)\end{array}$ & Soil pH & $\begin{array}{c}\text { Soil organic C } \\
\left(\mathrm{g} \mathrm{kg}^{-1}\right)\end{array}$ & $\begin{array}{c}\text { Soil } \\
\text { mineralizable } \\
\mathbf{N}\left(\mathbf{m g ~ k g}^{-1}\right)\end{array}$ & $\begin{array}{c}\text { Soil available } \\
\mathbf{P}\left(\mathbf{m g ~ k g}^{-1}\right)\end{array}$ & $\begin{array}{l}\text { Soil available } \\
\mathrm{K}\left(\mathrm{mg} \mathrm{kg}^{-1}\right)\end{array}$ & $\begin{array}{c}\text { Plant species } \\
\text { richness }\end{array}$ \\
\hline$N P-$ & $13.37 \pm 1.08 c$ & $7.98 \pm 0.06 b$ & $17.46 \pm 0.72 b$ & $265.00 \pm 12.38 a b$ & $5.01 \pm 0.21 a$ & $352.55 \pm 43.83 a$ & $7.80 \pm 0.66 b$ \\
\hline NP (Control) & $17.07 \pm 0.83 \mathrm{ab}$ & $8.11 \pm 0.08 a b$ & $16.85 \pm 0.99 b$ & $265.20 \pm 16.13 a b$ & $3.66 \pm 0.68 \mathrm{bc}$ & $316.80 \pm 59.48 a$ & $11.40 \pm 1.08 \mathrm{a}$ \\
\hline $\mathrm{NP}+$ & $19.33 \pm 1.22 \mathrm{a}$ & $8.17 \pm 0.03 a$ & $19.13 \pm 1.05 a b$ & $241.60 \pm 10.22 b$ & $3.60 \pm 0.27 b c$ & $311.59 \pm 34.52 a$ & $13.60 \pm 0.93 a$ \\
\hline$N+P-$ & $14.93 \pm 0.39 b c$ & $7.75 \pm 0.05 c$ & $20.18 \pm 0.85 a$ & $286.80 \pm 3.60 a$ & $4.82 \pm 0.35 a b$ & $325.59 \pm 29.85 a$ & $5.00 \pm 0.45 c$ \\
\hline$N+P$ & $16.77 \pm 1.30 \mathrm{ab}$ & $7.99 \pm 0.06 b$ & $21.07 \pm 0.49 a$ & $238.20 \pm 7.63 b$ & $4.35 \pm 0.26 a b$ & $355.64 \pm 50.86 a$ & $7.00 \pm 0.71 b c$ \\
\hline $\begin{array}{l}\mathrm{N}+\mathrm{P}+ \\
\text { Significance of }\end{array}$ & $19.18 \pm 0.70 a$ & $8.11 \pm 0.03 a b$ & $18.86 \pm 0.45 a b$ & $247.40 \pm 16.55 b$ & $3.08 \pm 0.40 c$ & $369.62 \pm 15.31 a$ & $6.60 \pm 1.08 b c$ \\
\hline $\mathrm{N}$ & 0.718 & 0.035 & 0.032 & 0.959 & 0.981 & 0.461 & 0.000 \\
\hline$P$ & 0.002 & 0.005 & 0.981 & 0.035 & 0.024 & 0.993 & 0.004 \\
\hline$N \times P$ & 0.661 & 0.266 & 0.035 & 0.099 & 0.355 & 0.702 & 0.061 \\
\hline Block & 0.931 & 0.677 & 0.931 & 0.430 & 0.615 & 0.999 & 0.334 \\
\hline
\end{tabular}

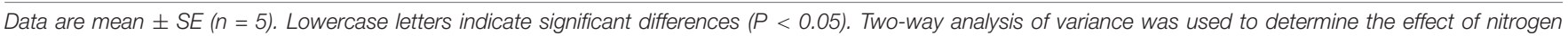

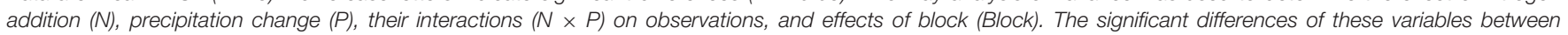
treatments were examined using Tukey's test at $P<0.05$, and significant effects $(P<0.05)$ are highlighted in bold. 


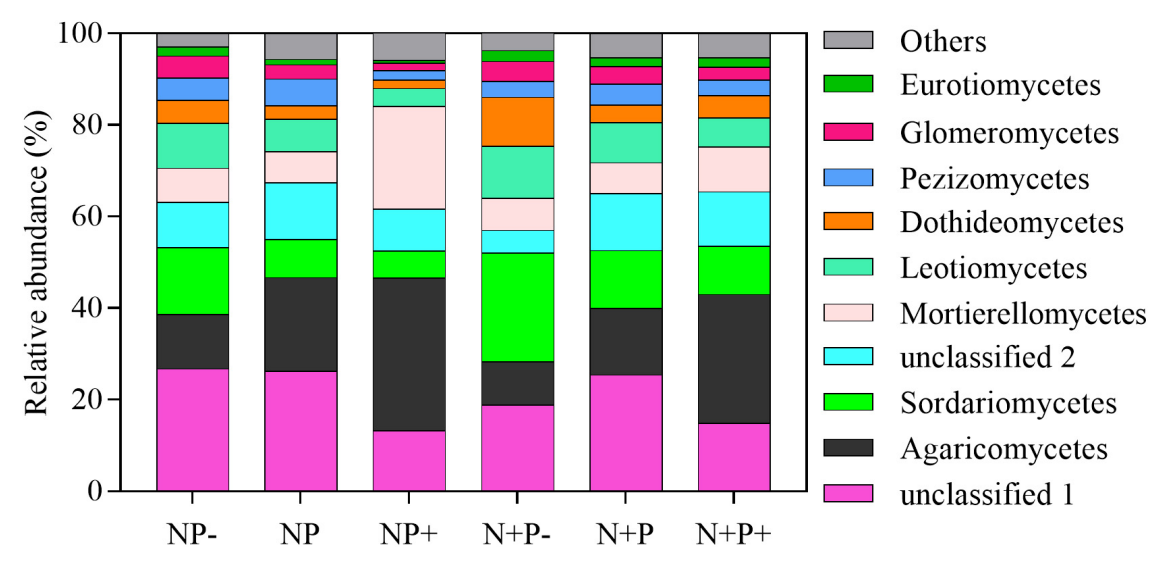

FIGURE 2 | Average relative abundances (\%) of the top 10 fungal groups at the class level found at each treatment. Others present the sum of other classes of fungi outside the top 10 in this study. N (ambient N), N + (N addition), P (ambient precipitation), P + (50\% added precipitation), and P- (50\% reduction in precipitation).

negatively and significantly related to plant available $\mathrm{N}$ and $\mathrm{P}$ content in soil. There were no significant relationships detected with SOC and plant available K content in soil (Table 2).

\section{Community Assembly of the Soil Fungal Community}

Beta diversity null modeling analysis showed that an effect size lesser than zero across treatments (Figure 4D) indicated that deterministic ecological processes (i.e., environmental filtering) were more important than neutral processes in soil fungal community assembly. Compared to that under NP (control) treatment, the importance of environmental filtering was decreased under $\mathrm{N}+\mathrm{P}-$ treatment (Figure 4D). The

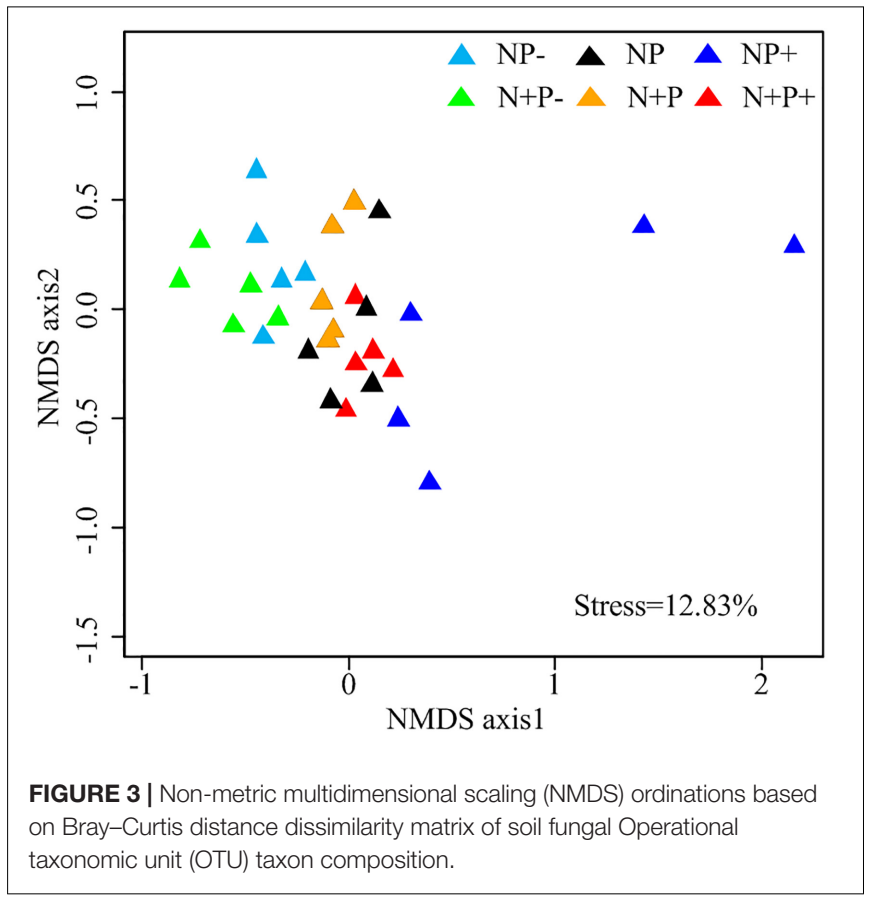

co-occurrence network analysis of fungi revealed that strong positive interactions among fungi OTUs were detected under all treatments (Figure 5), in which this positive interaction under NP + treatment was overwhelmingly stronger than all other treatments including NP (control) treatment. The mean of clustering coefficients was up to 0.639 , which was higher in NP + treatment than in NP (control) treatment and was lesser in NP treatment than in other treatments (Supplementary Table S4). Other network parameters are shown in Supplementary Table S4.

\section{DISCUSSION}

\section{Effects of Nitrogen Addition and Precipitation Changes on Relative Abundance and Diversity of Soil Fungi}

Several studies have shown that both nitrogen addition and precipitation changes have significant impacts on the relative abundance and diversity of soil fungi (Leff et al., 2015; Chen et al., 2017; Zhang et al., 2018). Here, experimental results also indicated that the relative abundances of soil fungal taxa were altered significantly under nitrogen addition and precipitation alteration (Figure 2 and Supplementary Table S1), suggesting that shifts in both nitrogen and precipitation may influence the ecological functions of soil fungal taxa in the alpine steppe ecosystem. Soil fungi play important roles in the interactions between plants and soil (Semchenko et al., 2018), especially in nutrient acquisition for plants (Bowles et al., 2018). Nitrogen addition and precipitation changes would induce changes in soil availability of nitrogen, soil moisture content, and soil $\mathrm{pH}$ (Serna-Chavez et al., 2013; Lu et al., 2014). These changes in soil environmental factors might decrease the importance of some fungal groups involved in nutrient absorption for plants (Leff et al., 2015) and result in alteration of the initial carbon allocation strategy of plants to fungi (Wei et al., 2013). The changes would motivate significant shifts in the relative abundance of soil fungi. In addition, significant changes in plant communities may be 

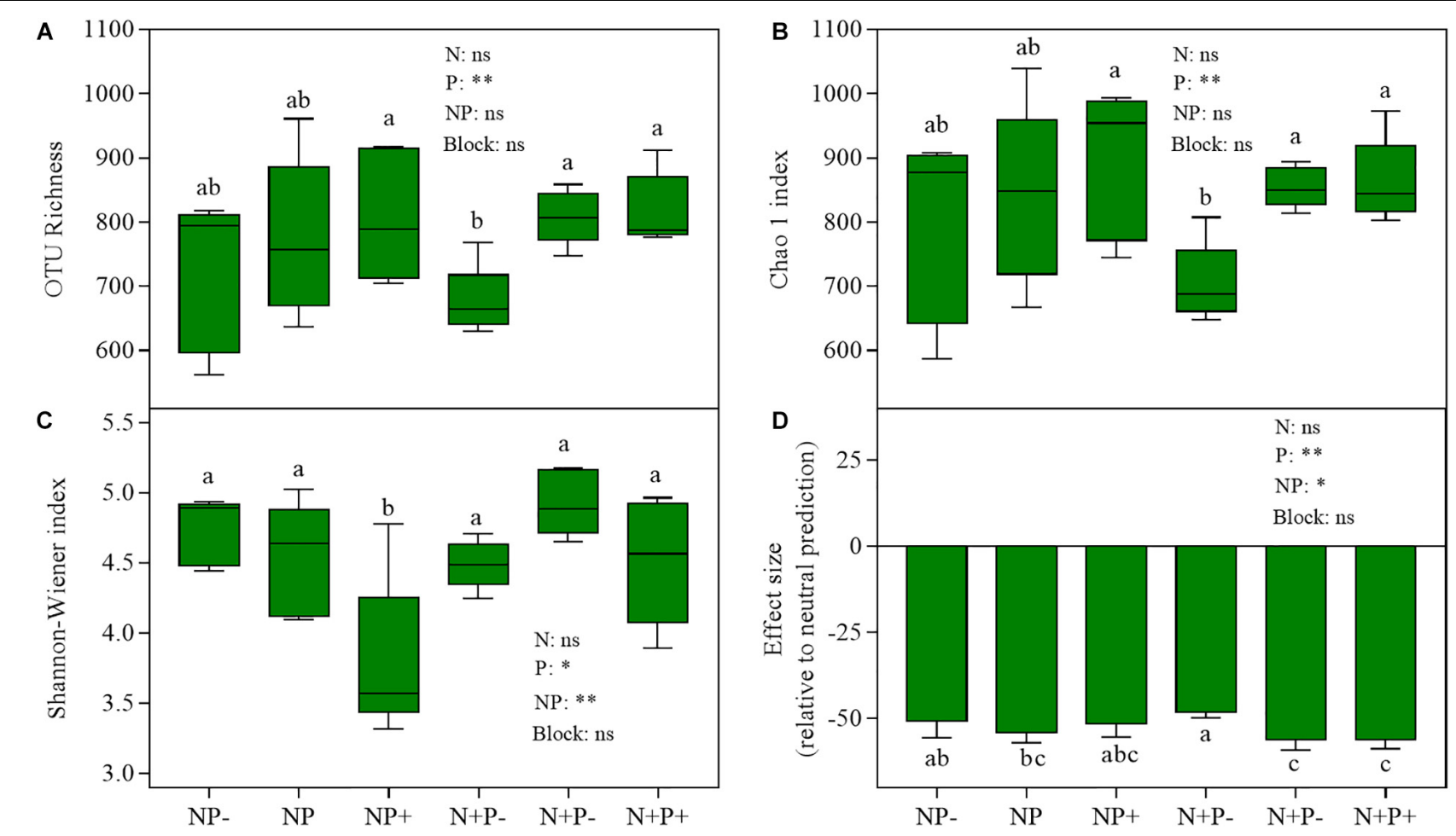

FIGURE 4 | Diversity and effect size relative to neutral prediction based on null model analysis of Bray-Curtis dissimilarity of soil fungal community across treatments. (A) OTU richness; (B) Chao 1 index; (C) Shannon-Wiener index; (D) effect size (relative to neutral prediction). Lowercase letters indicate significant differences $(P<0.05)$. Student's $t$-test was used to determine the difference between effect size of community assembly and zero, and significant differences of these diversity indicators between treatments were examined using Tukey's test at $P<0.05$.

another explanation for shifts in the relative abundance of soil fungi (Qin et al., 2020), since plant community changes would trigger shifts in soil fungal trophic groups (e.g., pathogenic and saprophytic fungi) (Makiola et al., 2019).

The relative abundance analysis also revealed a dynamic shift in Agaricomycetes and Sordariomycetes, with one falling and the other rising with the increasing gradient in precipitation

TABLE 2 | Spearman's correlation analysis between soil fungal community composition and soil environmental factors and plant species richness, and the response variable was the first axes of the non-metric multidimensional scaling (NMDS).

\begin{tabular}{lcc}
\hline Explanatory factor & \multicolumn{2}{c}{$\begin{array}{c}\text { Operational taxonomic unit (OTU) } \\
\text { community composition }\end{array}$} \\
\cline { 2 - 3 } & $\boldsymbol{r}$ & $\boldsymbol{P}$ \\
\hline Soil moisture & $\mathbf{0 . 5 2 8 3}$ & $\mathbf{0 . 0 0 2 7}$ \\
Soil pH & $\mathbf{0 . 4 9 9 5}$ & $\mathbf{0 . 0 0 4 9}$ \\
Soil organic C & -0.1275 & 0.5018 \\
Soil available N & $-\mathbf{0 . 4 4 2 5}$ & $\mathbf{0 . 0 1 4 3}$ \\
Soil available P & $-\mathbf{0 . 4 8 1 8}$ & $\mathbf{0 . 0 0 7 0}$ \\
Soil available K & -0.2289 & 0.2238 \\
Plant species richness & $\mathbf{0 . 5 3 6 6}$ & $\mathbf{0 . 0 0 2 2}$ \\
\hline
\end{tabular}

Significant correlations and P-values are in bold type.
(Figure 2). Specifically, the precipitation increment increased the relative abundance of Agaricomycetes but caused a decrease in that of Sordariomycetes. Furthermore, the relative abundance of Sordariomycetes increased in drought conditions. These observations suggested that the two taxa may be related to soil moisture. Results of function prediction showed that Agaricomycetes was closely related to dung saprotroph and plant saprotroph, whereas Sordariomycetes was closely related to soil animal pathogen (Figure 6). A previous study showed that soil animal abundance increased with increasing soil moisture (Sylvain et al., 2014), suggesting that the precipitation reduction treatment might enhance the likelihood of soil animals being infected by pathogens in alpine steppes (Delgado-Baquerizo et al., 2020). However, a study conducted in a subtropical forest reported that the abundance of Agaricomycetes increased in drought conditions (He et al., 2017), which was not consistent with our results. Agaricomycetes contained more undefined function groups (Figure 6A). Therefore, the responses of Agaricomycetes to precipitation may vary in different habitats.

Negative effects of nitrogen deposition on biodiversity, including microbial diversity, have been routinely observed (McClean et al., 2011; Zeng et al., 2016). In this study, nitrogen addition only slightly decreased the diversity of the soil fungal community (Figures 4A-C). However, significant negative effects of nitrogen addition combined with precipitation reduction on OTU richness and Chao 1 index were detected 


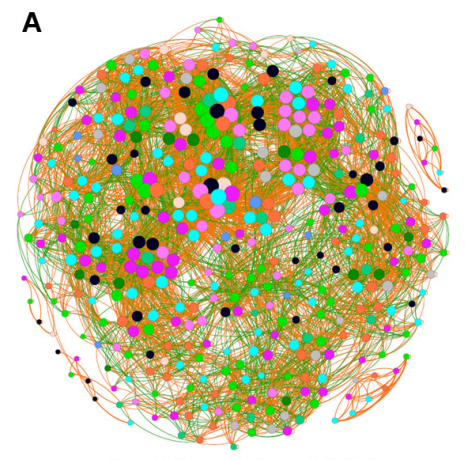

Positive links: 3706

Negative links: 2526

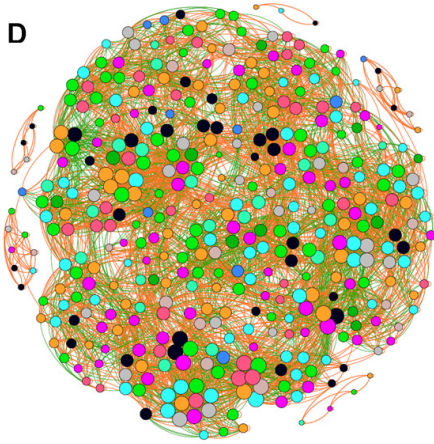

Positive links: 3175

Negative links: 2220

- Fungi_uncl Agaricomycetes

Leotiomycetes Dothideomycetes

Others

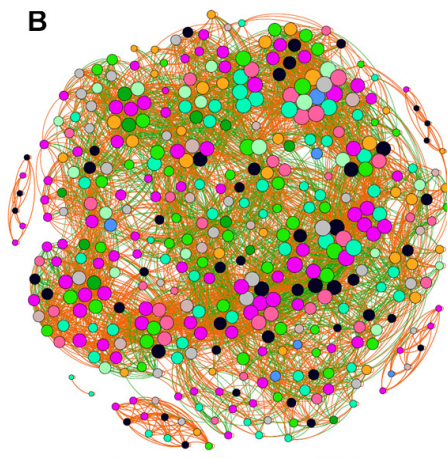

Positive links: 3502

Negative links: 2206

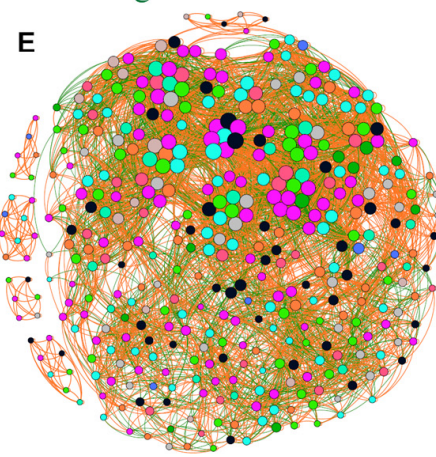

Positive links: 3761

Negative links: 2355

Sordariomycetes Ascomycota uncl

- Pezizomycetes Glomeromycetes

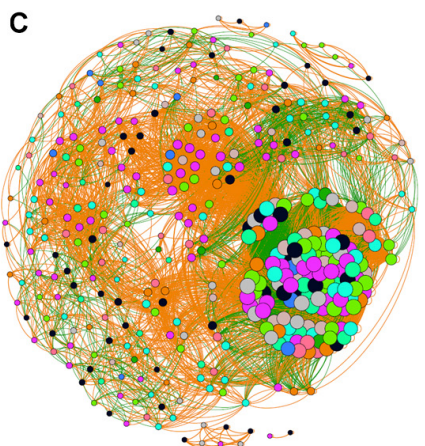

Positive links: 8284

Negative links: 3676

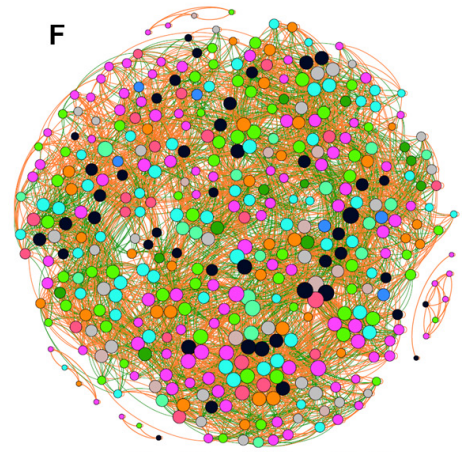

Positive links: 3148

Negative links: 2167

- Mortierellomycetes

- Eurotiomycetes

FIGURE 5 | Co-occurrence patterns of soil fungal taxon at OTU level for NP- treatment (A), NP treatment (B), NP + treatment (C), N + P- treatment (D), N + P (E), and $\mathrm{N}+\mathrm{P}+$ treatment $(\mathbf{F})$. The size of nodes was proportional to the link numbers of each node. Nodes in different colors are representative of the top 10 classes and other classes. Edges are shown with orange lines (positive interaction) and green lines (negative interaction). In each subfigure, only the top 400 OTUs and edges with Spearman's $\rho>0.60$ or $<-0.6$ and $P<0.05$ are shown.

(Figures 4A,B), suggesting that drought reinforces the negative effect of nitrogen addition on soil microbial diversity in the alpine steppe ecosystem. A previous study showed that nitrogen addition combined with elevated precipitation is beneficial for maintaining soil fungal diversity in the Stipa baicalensis temperate steppe (Zhang et al., 2018). Based on these observations, we speculated that, in the alpine steppe, drought had a stronger negative effect on microbial diversity than that of nitrogen addition. Moreover, only the Shannon-Wiener index decreased in precipitation addition, which may be related to the increase in the abundance of dominant soil fungal taxa under precipitation increment treatments (Figure 2).

\section{Relationships Between Soil Fungal Community Composition and Environmental Factors Under Nitrogen Addition and Precipitation Alteration}

Soil fungal community composition differed under nitrogen addition and precipitation change (Figure 3 and Table 3 ), which evidenced the responses of soil microbial composition to nitrogen deposition and precipitation change in the alpine steppe and may be related with the remission of nitrogen and precipitation limitation on the QTP (Zheng and Zhao, 2017). Nitrogen deposition and precipitation change could induce changes in availability of soil nitrogen, moisture, and other soil variables (Serna-Chavez et al., 2013; Xu et al., 2015) and subsequently affected soil fungal community composition (Zhang Y. et al., 2016). This result also further highlighted the significance of this study.

The soil moisture was strongly positively related with soil fungal community composition (Table 2). Precipitation driving the distribution pattern and community structure of a soil fungal community was reported at a temperate steppe (Wang et al., 2018). On the QTP, precipitation change altered the availability of soil moisture at an alpine steppe (Table 1), which may be the main reason for our result. Nitrogen addition would alter the availability of soil nitrogen and induces shifts in plant available $\mathrm{P}$ content in soil (Deng et al., 2017; Li et al., 2020) and then changed soil nutrient conditions for 

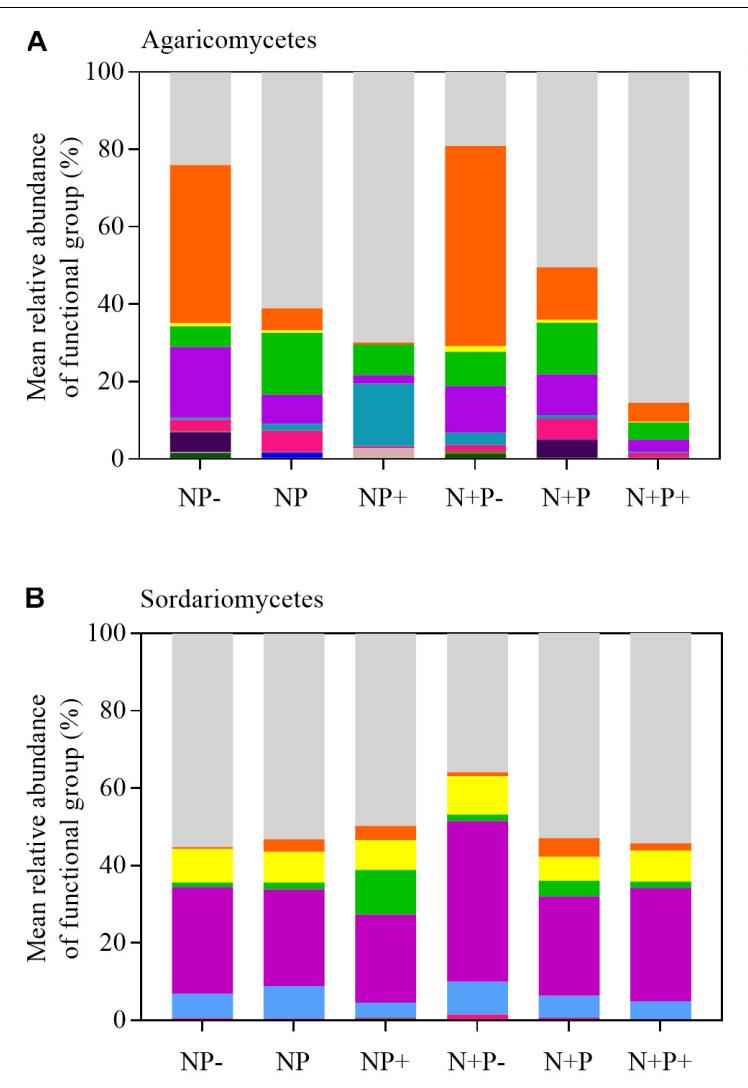

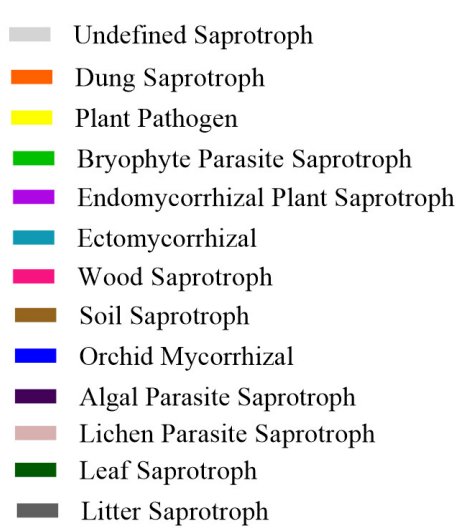

Undefined Saprotroph

Dung Saprotroph

Plant Pathogen

- Animal Pathogen

- Animal Pathogen Saprotroph

Endophyte

Plant Pathogen Saprotroph

Fungal Parasite

Wood Saprotroph

Leaf Saprotroph

- Plant Saprotroph

Fungal Parasite Saprotroph

FIGURE 6 | Compositions of fungal functional group (guild) inferred by FUNGuild, Agaricomycetes (A) and Sordariomycetes (B).

soil microbial community. These explained the significant correlation between soil fungal community composition and plant available $\mathrm{N}$ and $\mathrm{P}$ content in soil (Table 2). Soil $\mathrm{pH}$ was an important predictor for soil microbial community composition (Shen et al., 2013; Chen et al., 2017; Zhou et al., 2020) and played primary roles in community assemblage (Dumbrell et al., 2010; Wang et al., 2017; Tripathi et al., 2018; Cho et al., 2019). A significant positive relationship between soil $\mathrm{pH}$ and fungal community composition was also revealed (Table 2), which was consistent with previous studies. Change in plant species richness intuitively reflected plant community shift and also significantly related with fungal community composition, which could be explained by the shift in initial carbon allocation strategy of plants to fungi (Wei et al., 2013).

\section{Mechanism of Soil Fungal Community Assemblage Under Nitrogen Addition and Precipitation Alteration}

Beta diversity null modeling analysis has increasingly been employed to access the mechanism of community assemblage (Beck et al., 2015; Powell et al., 2015; Powell and Bennett, 2016). Here, the effect size of null modeling analysis showed that the soil fungal community was convergent across all treatments (Figure 4D), suggesting that deterministic ecological processes, which are largely environmental filtering, play primary and dominant roles in shaping the soil fungal community (Powell and Bennett, 2016). In addition to the $\mathrm{N}+\mathrm{P}-$ treatment, non-significant differences between others and NP (control) treatment were revealed, suggesting that overall soil fungal community assembly processes may be relatively stable. A previous study has shown that fungal communities are more stable than other microbial groups under climate change (de Vries et al., 2018). The long formation period of alpine steppes may be another reason for a relatively stable process of soil fungal community assemblage under climate change scenarios, since ecosystem development strongly influences belowground biodiversity (Delgado-Baquerizo et al., 2019). The 7-year period

TABLE 3 | Results of permutational multivariate analysis of variance (PERMANOVA) for fungal community composition, and significant effects $(P<0.05)$ are highlighted in bold.

\begin{tabular}{lccc}
\hline & \multicolumn{3}{c}{ Fungal community composition } \\
\cline { 2 - 4 } & $\boldsymbol{F}$ model & $\boldsymbol{R}^{\mathbf{2}}$ & $\boldsymbol{P}$-value \\
\hline $\mathrm{N}$ & 1.7505 & 0.0487 & $\mathbf{0 . 0 1 6}$ \\
$\mathrm{P}$ & 3.1996 & 0.1781 & $\mathbf{0 . 0 0 1}$ \\
$\mathrm{N} \times \mathrm{P}$ & 1.3753 & 0.0765 & $\mathbf{0 . 0 4 5}$ \\
Block & 1.2601 & 0.1403 & 0.062
\end{tabular}


of this field experiment was extremely short compared with the long period of alpine steppe formation in the QTP that may have led to a relatively stable process in soil fungal community assemblage. Similarly, a previous study reporting no significant responses of a fungal community to short-term changes in climate conditions (Zhang K. P. et al., 2016) supported our explanation. It should be noted that even though soil fungal communities were convergent across treatments, precipitation change and its interaction with nitrogen addition had significant effects on the community assembly process (Supplementary Table S3), which indicated that soil fungal community assembly processes may tend to neutralize processes under long-term nitrogen deposition and precipitation reduction in the future.

Co-occurrence network analysis is another powerful tool to explore the mechanism of microbial community assemblage (Barberán et al., 2012; Cardinale et al., 2015; Jiao et al., 2020). Here, stronger positive interactions between fungal OTUs were presented (Figure 5), suggesting a closer cooperation among fungal OTUs (Deng et al., 2012) and reflecting, to some extent, that soil fungi might tend to share similar soil niches. Interestingly, precipitation increment $(\mathrm{NP}+)$ treatment strongly enhances cluster degree than did control (NP) and other treatments (Figure 5C), which suggested that precipitation increment might trigger a soil ecological process and improve interactions of soil fungal taxon. The mean of clustering coefficients was up to 0.639 , which indicated closer relationships between OTUs (Jiao et al., 2020). These speculations might support results that deterministic processes played more important roles in shaping soil fungal community at the alpine steppe on the QTP than neutral ecological processes. Although co-occurrence network analysis was used to infer biotic interactions, we acknowledged shortcomings of the network analysis due to difficulty in accurately detecting community assembly ecological processes (Carr et al., 2019). Therefore, incorporating more experiments or more sophisticated approaches into the research framework will be necessary in the future.

\section{CONCLUSION}

This study explored the responses of soil fungal community composition, diversity, and community assembly processes to nitrogen addition and precipitation changes at an alpine

\section{REFERENCES}

Adams, R. I., Miletto, M., Taylor, J. W., and Bruns, T. D. (2013). Dispersal in microbes: fungi in indoor air are dominated by outdoor air and show dispersal limitation at short distances. ISME J. 7, 1460-1460. doi: 10.1038/ismej.2013.84

Amend, A. S., Matulich, K. L., and Martiny, J. B. H. (2015). Nitrogen addition, not initial phylogenetic diversity, increases litter decomposition by fungal communities. Front. Microbiol. 6:109. doi: 10.3389/fmicb.2015.00109

Bao, S. D. (2005). Agricultural Chemical Analysis of Soil. Beijing: China Agriculture Press.

Barberán, A., Bates, S. T., Casamayor, E. O., and Fierer, N. (2012). Using network analysis to explore co-occurrence patterns in soil microbial communities. ISME J. 6, 343-351. doi: 10.1038/ismej.2011.119 steppe on the northeastern Qinghai-Tibetan Plateau. Soil fungal community composition and diversity were altered significantly by nitrogen addition and precipitation change, while the convergent processes of fungal community assembly were also altered, even though the dominance of deterministic ecological processes was not changed. The study suggested that soil fungal communities at alpine steppes on the QTP may change a lot under long-term global change scenarios in the future. Future works investigating more comprehensive environmental factors and using more research methods simultaneously are essential to fully understand the construction of fungal communities in nature.

\section{DATA AVAILABILITY STATEMENT}

The datasets presented in this study can be found in online repositories. The names of the repository/repositories and accession number(s) can be found in the article/Supplementary Material.

\section{AUTHOR CONTRIBUTIONS}

YX, CL, and GZ designed the experiments. YX and GZ jointly wrote the manuscript. YY assisted with the field sampling. YP and YY participated in the discussions. All authors contributed to the article and approved the submitted version.

\section{FUNDING}

This work was jointly supported by the National Key Research and Development Program of China (2019YFC0507404), the Natural Science Foundation of Qinghai Province (2019-ZJ-910), and the International Exchange and Cooperation Project of Qinghai Province (2019-HZ-807).

\section{SUPPLEMENTARY MATERIAL}

The Supplementary Material for this article can be found online at: https://www.frontiersin.org/articles/10.3389/fmicb. 2020.579072/full\#supplementary-material

Beck, S., Powell, J. R., Drigo, B., Cairney, J. W. G., and Anderson, I. C. (2015). The role of stochasticity differs in the assembly of soil- and root-associated fungal communities. Soil Biol. Biochem. 80, 18-25. doi: 10.1016/j.soilbio.2014.09.010

Bowles, T. M., Jackson, L. E., and Cavagnaro, T. R. (2018). Mycorrhizal fungi enhance plant nutrient acquisition and modulate nitrogen loss with variable water regimes. Glob. Chang. Biol. 24, E171-E182. doi: 10.1111/gcb. 13884

Cardinale, M., Grube, M., Erlacher, A., Quehenberger, J., and Berg, G. (2015). Bacterial networks and co-occurrence relationships in the lettuce root microbiota. Environ. Microbiol. 17, 239-252. doi: 10.1111/1462-2920.12686

Carr, A., Diener, C., Baliga, N. S., and Gibbons, S. M. (2019). Use and abuse of correlation analyses in microbial ecology. ISME J. 13, 2647-2655. doi: 10.1038/ s41396-019-0459-z 
Chen, S. F., Zhou, Y. Q., Chen, Y. R., and Gu, J. (2018). fastp: an ultra-fast all-in-one FASTQ preprocessor. Bioinformatics 34, 884-890. doi: 10.1093/bioinformatics/ bty560

Chen, Y. L., Xu, Z. W., Xu, T. L., Veresoglou, S. D., Yang, G. W., and Chen, B. D. (2017). Nitrogen deposition and precipitation induced phylogenetic clustering of arbuscular mycorrhizal fungal communities. Soil Biol. Biochem. 115, 233-242. doi: 10.1016/j.soilbio.2017.08.024

Cho, H. J., Tripathi, B. M., Moroenyane, I., Takahashi, K., Kerfahi, D., Dong, K., et al. (2019). Soil $\mathrm{pH}$ rather than elevation determines bacterial phylogenetic community assembly on Mt. Norikura. FEMS Microbiol. Ecol. 95:fiy216. doi: 10.1093/femsec/fiy216

Davison, J., Moora, M., Opik, M., Adholeya, A., Ainsaar, L., Ba, A., et al. (2015). Global assessment of arbuscular mycorrhizal fungus diversity reveals very low endemism. Science 349, 970-973. doi: 10.1126/science.aab1161

de Vries, F. T., Griffiths, R. I., Bailey, M., Craig, H., Girlanda, M., and Gweon, H. S. (2018). Soil bacterial networks are less stable under drought than fungal networks. Nat. Commun. 9:3033. doi: 10.1038/s41467-018-05516-7

Delgado-Baquerizo, M., Bardgett, R. D., Vitousek, P. M., Maestre, F. T., Williams, M. A., and Fierer, N. (2019). Changes in belowground biodiversity during ecosystem development. Proc. Natl. Acad. Sci. U.S.A. 116, 6891-6896. doi: 10. 1073/pnas.1818400116

Delgado-Baquerizo, M., Guerra, C. A., Cano-Diaz, C., Egidi, E., Wang, J. T., Eisenhauer, N., et al. (2020). The proportion of soil-borne pathogens increases with warming at the global scale. Nat. Clim. Chang 10, 550-554. doi: 10.1038/ s41558-020-0759-3

Deng, Q., Hui, D. F., Dennis, S., and Reddy, K. C. (2017). Responses of terrestrial ecosystem phosphorus cycling to nitrogen addition: a meta-analysis. Glob. Ecol. Biogeogr. 26, 713-728. doi: 10.1111/geb.12576

Deng, Y., Jiang, Y. H., Yang, Y. F., He, Z. L., Luo, F., and Zhou, J. Z. (2012). Molecular ecological network analyses. BMC Bioinformatics 13:113. doi: 10. 1186/1471-2105-13-113

Dini-Andreote, F., Stegen, J. C., van Elsas, J. D., and Salles, J. F. (2015). Disentangling mechanisms that mediate the balance between stochastic and deterministic processes in microbial succession. Proc. Natl. Acad. Sci. U.S.A. 112, E1326-E1332. doi: 10.1073/pnas.1414261112

Dumbrell, A. J., Nelson, M., Helgason, T., Dytham, C., and Fitter, A. H. (2010). Relative roles of niche and neutral processes in structuring a soil microbial community. ISME J. 4, 337-345. doi: 10.1038/ismej.2009.122

Edgar, R. C. (2013). UPARSE: highly accurate OTU sequences from microbial amplicon reads. Nat. Methods 10, 996-998. doi: 10.1038/Nmeth. 2604

Feng, M. M., Adams, J. M., Fan, K. K., Shi, Y., Sun, R. B., and Chu, H. Y. (2018). Long-term fertilization influences community assembly processes of soil diazotrophs. Soil Biol. Biochem. 126, 151-158. doi: 10.1016/j.soilbio.2018.08.021

Frac, M., Hannula, S. E., Belka, M., and Jedryczka, M. (2018). Fungal biodiversity and their role in soil health. Front. Microbiol. 9:707. doi: 10.3389/fmicb.2018. 00707

Gao, C., Montoya, L., Xu, L., Madera, M., Hollingsworth, J., and Taylor, J. W. (2020). Fungal community assembly in drought-stressed sorghum shows stochasticity, selection, and universal ecological dynamics. Nat. Commun. 11, 34-47. doi: 10.1038/s41467-019-13913-9

He, D., Shen, W. J., Eberwein, J., Zhao, Q., Ren, L. J., and Wu, Q. L. L. (2017). Diversity and co-occurrence network of soil fungi are more responsive than those of bacteria to shifts in precipitation seasonality in a subtropical forest. Soil Biol. Biochem. 115, 499-510. doi: 10.1016/j.soilbio.2017.09.023

Hutchins, D. A., Jansson, J. K., Remais, J. V., Rich, V. I., Singh, B. K., and Trivedi, P. (2019). Climate change microbiology - problems and perspectives. Nat. Rev. Microbiol. 17, 391-396. doi: 10.1038/s41579-019-0178-5

Jiao, S., Yang, Y. F., Xu, Y. Q., Zhang, J., and Lu, Y. H. (2020). Balance between community assembly processes mediates species coexistence in agricultural soil microbiomes across eastern China. ISME J. 14, 202-216. doi: 10.1038/s41396019-0522-9

Koljalg, U., Nilsson, R. H., Abarenkov, K., Tedersoo, L., Taylor, A. F. S., Bahram, M., et al. (2013). Towards a unified paradigm for sequencebased identification of fungi. Mol. Ecol. 22, 5271-5277. doi: 10.1111/mec. 12481

Leff, J. W., Jones, S. E., Prober, S. M., Barberan, A., Borer, E. T., and Fierer, N. (2015). Consistent responses of soil microbial communities to elevated nutrient inputs in grasslands across the globe. Proc. Natl. Acad. Sci. U.S.A. 112, 10967-10972. doi: 10.1073/pnas.1508382112

Li, C. B., Zheng, Z., Peng, Y. F., Nie, X. Q., Yang, L. C., Xiao, Y. M., et al. (2019). Precipitation and nitrogen addition enhance biomass allocation to aboveground in an alpine steppe. Ecol. Evol. 9, 12193-12201. doi: 10.1002/ece3. 5706

Li, S., Dong, S. K., Shen, H., Xu, Y. D., Gao, X. X., Han, Y. H., et al. (2020). Nitrogen addition gradient can regulate the environmental filtering of soil potassium or phosphorus in shaping the community assembly of alpine meadow. Ecol. Indic. 109:105774. doi: 10.1016/j.ecolind.2019.105774

Lü, C. Q., and Tian, H. Q. (2007). Spatial and temporal patterns of nitrogen deposition in China: Synthesis of observational data. J. Geophys. Res. 112:D22S05. doi: 10.1029/2006jd007990

Lu, X. K., Mao, Q. G., Gilliam, F. S., Luo, Y. Q., and Mo, J. M. (2014). Nitrogen deposition contributes to soil acidification in tropical ecosystems. Glob. Chang. Biol. 20, 3790-3801. doi: 10.1111/gcb.12665

Luo, Z. M., Liu, J. X., Zhao, P. Y., Jia, T., Li, C., and Chai, B. F. (2019). Biogeographic patterns and assembly mechanisms of bacterial communities differ between habitat generalists and specialists across elevational gradients. Front. Microbiol. 10:169. doi: 10.3389/fmicb.2019.00169

Ma, Z. Y., Liu, H. Y., Mi, Z. R., Zhang, Z. H., Wang, Y. H., Xu, W., et al. (2017). Climate warming reduces the temporal stability of plant community biomass production. Nat. Commun. 8, 15378-15384. doi: 10.1038/ncomms 15378

Magoč, T., and Salzberg, S. L. (2011). FLASH: fast length adjustment of short reads to improve genome assemblies. Bioinformatics 27, 2957-2963. doi: 10.1093/ bioinformatics/btr507

Makiola, A., Dickie, I. A., Holdaway, R. J., Wood, J. R., Orwin, K. H., and Glare, T. R. (2019). Land use is a determinant of plant pathogen alpha- but not beta-diversity. Mol. Ecol. 28, 3786-3798. doi: 10.1111/mec.15177

McClean, C. J., van den Berg, L. J. L., Ashmore, M. R., and Preston, C. D. (2011). Atmospheric nitrogen deposition explains patterns of plant species loss. Glob. Change Biol. 17, 2882-2892. doi: 10.1111/j.1365-2486.2011.02462.x

Miehe, G., Miehe, S., Bach, K., Nolling, J., Hanspach, J., Reudenbach, C., et al. (2011). Plant communities of central Tibetan pastures in the Alpine Steppe/Kobresia pygmaea ecotone. J. Arid. Environ. 75, 711-723. doi: 10.1016/ j.jaridenv.2011.03.001

Mori, A. S., Fujii, S., Kitagawa, R., and Koide, D. (2015). Null model approaches to evaluating the relative role of different assembly processes in shaping ecological communities. Oecologia 178, 261-273. doi: 10.1007/s00442-014-3170-9

Na, X. F., Yu, H. L., Wang, P., Zhu, W. W., Niu, Y. B., and Huang, J. Y. (2019). Vegetation biomass and soil moisture coregulate bacterial community succession under altered precipitation regimes in a desert steppe in northwestern China. Soil Biol. Biochem. 136:107520. doi: 10.1016/j.soilbio. 2019.107520

Nemergut, D. R., Schmidt, S. K., Fukami, T., O’Neill, S. P., Bilinski, T. M., and Ferrenberg, S. (2013). Patterns and processes of microbial community assembly. Microbiol. Rev. 77, 342-356. doi: 10.1128/Mmbr.00051-12

Nguyen, N. H., Song, Z. W., Bates, S. T., Branco, S., Tedersoo, L., Menke, J., et al. (2016). FUNGuild: An open annotation tool for parsing fungal community datasets by ecological guild. Fungal Ecol. 20, 241-248. doi: 10.1016/j.funeco. 2015.06.006

Oksanen, J., Blanchet, F. G., Friendly, M., Kindt, R., Legendre, P., McGlinn, D., et al. (2019). vegan: Community Ecology Package. $R$ Package Version 2.54. Avaliable online at: https://CRAN.R-project.org/package=vegan (accessed January 9, 2019).

Peng, Y. F., and Yang, Y. H. (2016). Allometric biomass partitioning under nitrogen enrichment: Evidence from manipulative experiments around the world. Sci. Rep. 6:28918. doi: 10.1038/srep28918

Powell, J. R., and Bennett, A. E. (2016). Unpredictable assembly of arbuscular mycorrhizal fungal communities. Pedobiologia 59, 11-15. doi: 10.1016/j.pedobi. 2015.12.001

Powell, J. R., Karunaratne, S., Campbell, C. D., Yao, H. Y., Robinson, L., and Singh, B. K. (2015). Deterministic processes vary during community assembly for ecologically dissimilar taxa. Nat. Commun. 6:8444. doi: 10.1038/ncomms9444

Qin, C., Zhu, K., Chiariello, N. R., Field, C. B., and Peay, K. G. (2020). Fire history and plant community composition outweigh decadal multi-factor global change as drivers of microbial composition in an annual grassland. J. Ecol. 108, 611-625. doi: 10.1111/1365-2745.13284 
R Core Team (2015). R: A Language and Environment for Statistical Computing. Vienna: R Foundation for Statistical Computing.

Revelle, W. (2018). psych: Procedures for Personality and Psychological Research. Evanston, IL: Northwestern University.

Semchenko, M., Leff, J. W., Lozano, Y. M., Saar, S., Davison, J., and Bardgett, R. D. (2018). Fungal diversity regulates plant-soil feedbacks in temperate grassland. Sci. Adv. 4:eaau4578. doi: 10.1126/sciadv.aau4578

Serna-Chavez, H. M., Fierer, N., and van Bodegom, P. M. (2013). Global drivers and patterns of microbial abundance in soil. Glob. Ecol. Biogeogr. 22, 1162-1172. doi: $10.1111 /$ geb.12070

Shen, C. C., Xiong, J. B., Zhang, H. Y., Feng, Y. Z., Lin, X. G., and Chu, H. Y. (2013). Soil $\mathrm{pH}$ drives the spatial distribution of bacterial communities along elevation on changbai mountain. Soil Biol. Biochem. 57, 204-211. doi: 10.1016/j.soilbio. 2012.07.013

Sylvain, Z. A., Wall, D. H., Cherwin, K. L., Peters, D. P. C., Reichmann, L. G., and Sala, O. E. (2014). Soil animal responses to moisture availability are largely scale, not ecosystem dependent: insight from a cross-site study. Glob. Chang Biol. 20, 2631-2643. doi: $10.1111 /$ gcb.12522

Tedersoo, L., Bahram, M., Polme, S., Koljalg, U., Yorou, N. S., Wijesundera, R., et al. (2014). Global diversity and geography of soil fungi. Science 346:1256688. doi: $10.1126 /$ science. 1256688

Tripathi, B. M., Stegen, J. C., Kim, M., Dong, K., Adams, J. M., and Lee, Y. K. (2018). Soil $\mathrm{pH}$ mediates the balance between stochastic and deterministic assembly of bacteria. ISME J. 12, 1072-1083. doi: 10.1038/s41396-018-0082-4

Vavrek, M. J. (2011). fossil: palaeoecological and palaeogeographical analysis tools. Palaeontol. Electronica 14:16.

Wang, D., Rui, Y. C., Ding, K., Cui, X. Y., Hao, Y. B., and Wang, Y. F. (2018). Precipitation drives the biogeographic distribution of soil fungal community in Inner Mongolian temperate grasslands. J. Soils Sediments 18, 222-228. doi: $10.1007 / \mathrm{s} 11368-017-1727-\mathrm{z}$

Wang, Q., Garrity, G. M., Tiedje, J. M., and Cole, J. R. (2007). Naive bayesian classifier for rapid assignment of rRNA sequences into the new bacterial taxonomy. Appl. Environ. Microbiol. 73, 5261-5267. doi: 10.1128/Aem.0006207

Wang, Y. S., Li, C. N., Kou, Y. P., Wang, J. J., Tu, B., Li, H., et al. (2017). Soil pH is a major driver of soil diazotrophic community assembly in qinghai-tibet alpine meadows. Soil Biol. Biochem. 115, 547-555. doi: 10.1016/j.soilbio.2017.09.024

Wei, C. Z., Yu, Q., Bai, E., Lu, X. T., Li, Q., and Han, X. G. (2013). Nitrogen deposition weakens plant-microbe interactions in grassland ecosystems. Glob. Change Biol. 19, 3688-3697. doi: 10.1111/gcb.12348

Xu, Z. W., Ren, H. Y., Cai, J. P., Wang, R. Z., He, P., Li, M. H., et al. (2015). Antithetical effects of nitrogen and water availability on community similarity of semiarid grasslands: evidence from a nine-year manipulation experiment. Plant Soil 397, 357-369. doi: 10.1007/s11104-015-2634-y
Yang, Y. H. (2018). Ecological processes in alpine ecosystems under changing environment. J. Plant Ecol. 42, 1-5. doi: 10.17521/cjpe.2018. 0048

Zeng, J., Liu, X. J., Song, L., Lin, X. G., Zhang, H. Y., Shen, C. C., et al. (2016). Nitrogen fertilization directly affects soil bacterial diversity and indirectly affects bacterial community composition. Soil Biol. Biochem. 92, 41-49. doi: 10.1016/j. soilbio.2015.09.018

Zhang, H. F., Liu, H. M., Zhao, J. N., Wang, L. L., Li, G., and Yang, D. L. (2017). Elevated precipitation modifies the relationship between plant diversity and soil bacterial diversity under nitrogen deposition in Stipa baicalensis steppe. Appl. Soil. Ecol. 119, 345-353. doi: 10.1016/j.apsoil.2017. 06.005

Zhang, H. F., Wang, L. L., Liu, H. M., Zhao, J. N., Li, G., and Yang, D. L. (2018). Nitrogen deposition combined with elevated precipitation is conducive to maintaining the stability of the soil fungal diversity on the Stipa baicalensis steppe. Soil Biol. Biochem. 117, 135-138. doi: 10.1016/j.soilbio.2017. 11.004

Zhang, K. P., Shi, Y., Jing, X., He, J. S., Sun, R. B., and Chu, H. Y. (2016). Effects of short-term warming and altered precipitation on soil microbial communities in alpine grassland of the tibetan plateau. Front. Microbiol. 7:1032. doi: 10.3389/ fmicb.2016.01032

Zhang, Y., Dong, S. K., Gao, Q. Z., Liu, S. L., Zhou, H. K., and Wang, X. X. (2016). Climate change and human activities altered the diversity and composition of soil microbial community in alpine grasslands of the qinghai-tibetan plateau. Sci. Total Environ. 562, 353-363. doi: 10.1016/j.scitotenv.2016.03.221

Zheng, D., and Zhao, D. S. (2017). Characteristics of natural environment of the Tibetan plateau. Sci. Technol. Rev. 35, 13-22.

Zhou, Z. H., Wang, C. K., and Luo, Y. Q. (2020). Meta-analysis of the impacts of global change factors on soil microbial diversity and functionality. Nat. Commun. 11:3072. doi: 10.1038/s41467-020-16881-7

Zong, N., Shi, P. L., Song, M. H., Zhang, X. Z., Jiang, J., and Chai, X. (2016). Nitrogen critical loads for an alpine meadow ecosystem on the tibetan plateau. Environ. Manag. 57, 531-542. doi: 10.1007/s00267-015-0626-6

Conflict of Interest: The authors declare that the research was conducted in the absence of any commercial or financial relationships that could be construed as a potential conflict of interest.

Copyright (๑) 2020 Xiao, Li, Yang, Peng, Yang and Zhou. This is an open-access article distributed under the terms of the Creative Commons Attribution License (CC BY). The use, distribution or reproduction in other forums is permitted, provided the original author(s) and the copyright owner(s) are credited and that the original publication in this journal is cited, in accordance with accepted academic practice. No use, distribution or reproduction is permitted which does not comply with these terms. 